\title{
PENERAPAN MODEL PEMBELAJARAN KOOPERATIF TIPE SNOWBALL THROWING UNTUK MENINGKATKAN HASIL BELAJAR SISWA PADA MATA PELAJARAN PPKn KELAS XI IPS1 SMA DWIJENDRA DENPASAR TAHUN PELAJARAN 2018/2019
}

\author{
I Ketut Rindawan \\ Program Studi Pendidikan Pancasila dan Kewarganegaraan, Fakultas Keguruan Dan Ilmu Pendidikan \\ Universitas Dwijendra Denpasar \\ email : rindawan@undwi.ac.id \\ Apriani Roku Wanggu \\ Program Studi Pendidikan Pancasila dan Kewarganegaraan, Fakultas Keguruan Dan Ilmu Pendidikan \\ Universitas Dwijendra Denpasar \\ email : eryani175@gmail.com
}

\begin{abstract}
Abstrak
Penggunaan Model Pembelajaran Kooperatif Tipe Snowball Throwing cocok diterapkan di kelas XI IPS 1 SMA Dwijendra Denpasar karena menurut pendapat para siswa kelas XI IPS1 SMA Dwijendra Denpasar, mereka masih senang belajar sambil bermain. Model pembelajaran ini mampu mendorong siswa lebih aktif dan kreatif dalam kegiatan pembelajaran. Berdasarkan uraian tersebut peneliti bermaksud melakukan penelitian dengan judul "Penerapan Model Pembelajaran Kooperatif Tipe Snowball Throwing untuk Meningkatkan Hasil Belajar Siswa Pada Mata Pelajaran PPKn Kelas XI IPS 1 SMA Dwijendra Denpasar Tahun Pelajaran 2018/2019”. Penelitian ini merupakan Penelitian Tindakan Kelas yang dilaksanakan selama dua siklus dengan subjek penelitian siswa kelas XI IPS 1 SMA Dwijendra Denpasar Tahun Pelajaran 2018/2019 yang berjumlah 35 siswa, rumusan masalah yang dikemukakan dalam penelitian ini adalah apakah penerapan Model Pembelajaran Kooperatif Tipe Snowball Throwing Dapat Meningkatkan Hasil Belajar PPKn Siswa Kelas XI IPS 1 SMA Dwijendra Denpasar Tahun Pelajaran 2018/2019?. Penelitian ini bertujuan untuk meningkatkan Hasil Belajar Siswa pada mata pelajaran PPKn melalui Penerapan Model Pembelajaran Kooperatif Tipe Snowball Throwing pada siswa kelas XI IPS 1 SMA Dwijendra Denpasar Tahun Pelajaran 2018/2019. Teknik pengumpulan data yang digunakan dalam penelitian ini adalah observasi partisipasi, dan dokumentasi. Teknik analisis data yang digunakan adalah analisis data kuantitatif dengan persentase. Analisis ini dilakukan dengan cara menghitung persentase masing-masing indikator dan rata-rata keseluruhan indikator, menyajikan data, dan menarik kesimpulan. Hasil penelitian menunjukkan bahwa Implementasi Model Pembelajaran Kooperatif Tipe Snowball Throwing dapat meningkatkan Hasil Belajar Siswa Pada Mata Pelajaran PPKn Kelas XI IPS 1 SMA Dwijendra Denpasar Tahun Pelajaran 2018/2019 yang dibuktikan dengan adanya peningkatan skor di setiap indikator Hasil Belajar PPKn dari siklus I ke siklus II, serta peningkatan skor rata-rata hasil belajar PPKn dari siklus I sebesar 80,24\% menjadi 91,84\% pada siklus II atau meningkat sebesar $11,6 \%$.
\end{abstract}

Kata Kunci: Snowball Throwing, Hasil Belajar PPKn

\begin{abstract}
The use of the Snowball Throwing Cooperative Learning Model is suitable to be applied in class XI IPS 1 of SMA Dwijendra Denpasar because in the opinion of students of class XI IPS1 of Dwijendra Denpasar High School, they still enjoy learning while playing. This learning model is able to encourage students to be more active and creative in learning activities. Based on the description, the researcher intends to conduct research with the title "Application of the Snowball Throwing Cooperative Learning Model to Improve Student Learning Outcomes in Civics Class XI IPS 1 Subjects at SMA Dwijendra Denpasar in 2018/2019 Academic Year". This research is a Class Action Research conducted over two cycles with research subjects in class XI IPS 1 of SMA Dwijendra Denpasar in the 2018/2019 Academic Year totaling 35 students, the formulation of the problem raised in this study was whether the application of the Snowball Throwing Cooperative Learning Model Can Improve Learning Outcomes in Civics Class XI IPS 1 High School Students Dwijendra Denpasar Academic Year 2018/2019?. This study aims to improve Student Learning Outcomes in Civics subjects through the Implementation of the Snowball Throwing
\end{abstract}


Cooperative Learning Model in class XI IPS 1 students at Dwijendra Denpasar High School in 2018/2019 Academic Year. Data collection techniques used in this study were observation of participation, and documentation. The data analysis technique used is quantitative data analysis with percentages. This analysis is done by calculating the percentage of each indicator and the average of all indicators, presenting data, and drawing conclusions. The results showed that the implementation of the Snowball Throwing Cooperative Learning Model could improve Student Learning Outcomes in Civics Class XI IPS 1 Subjects in SMA Dwijendra Denpasar Academic Year 2018/2019 as evidenced by an increase in scores in each indicator of Civics Learning Outcomes from cycle I to cycle II, and an increase in the average score of PPKn learning outcomes from the first cycle by $80.24 \%$ to $91.84 \%$ in the second cycle or an increase of $11.6 \%$.

Keywords: Snowball Throwing, Learning Outcomes in Civics

\section{PENDAhuluan}

Pendidikan merupakan aspek penting dalam pencapaian cita-cita suatu bangsa. Melalui sistem pendidikan yang baik dan optimal pengaplikasiannya, maka akan tercapai tujuan Pendidikan Nasional guna mewujudkan bangsa yang maju dan membangun karakter bangsa yang bermartabat. Menurut UU No. 20 tahun 2003 Bab I pasal 1 ayat 1 tentang:

"Sistem Pendidikan Nasional menyatakan bahwa: Pendidikan adalah usaha sadar dan terencana untuk mewujudkan suasana belajar dan proses pembelajaran agar siswa secara aktif mengembangkan potensi dirinya untuk memiliki kekuatan spiritual keagamaan, pengendalian diri, kepribadian, kecerdasan, akhlak mulia, serta keterampilan yang diperlukan dirinya dan masyarakat, bangsa dan negara".

Dari pengertian tersebut dapat disimpulkan bahwa pendidikan merupakan suatu proses yang dilakukan untuk mengembangkan potensi siswa agar dapat menjadi pribadi yang berkualitas demi menciptakan kehidupan bangsa yang cerdas. Kecerdasan suatu bangsa tidak hanya berkaitan dengan ilmu pengetahuan, namun juga mampu mengendalikan diri dengan kepribadian yang baik. Tujuan pendidikan dapat dicapai dengan pelaksanaan proses pembelajaran yang berkualitas. Proses pembelajaran merupakan interaksi antara siswa dengan guru. Model pembelajaran mempengaruhi ketercapaian proses pembelajaran. Guru perlu menerapkan model yang sesuai dengan kondisi dan perilaku siswa. SMA Dwijendra Denpasar merupakan salah satu sekolah yang cepat beradaptasi dengan peraturan dan perubahan kurikulum yang ada. Hal ini dibuktikan dengan penerapan kurikulum 2013 revisi di sekolah tersebut. Berdasarkan pengamatan terhadap proses pembelajaran yang dilakukan saat observasi awal saat PPL pada tanggal 18 Oktober 2019 di kelas XI IPS1 SMA Dwijendra Denpasar Tahun Pelajaran 2018/2019 pada mata pelajaran PPKn, ditemukan masalah yaitu siswa kurang aktif selama proses pembelajaran walaupun guru telah mendorong mereka untuk berani bertanya, menjawab, atau berpendapat. Pada saat pembelajaran berlangsung guru masih menggunakan metode konvensional, yaitu metode ceramah dan latihan. Secara keseluruhan dari 35 siswa terdapat 5 orang siswa yang aktif bertanya dan memberikan pendapat mengenai materi yang dijelaskan, sisanya sebanyak 30 siswa masih belum aktif 
ketika guru memberikan waktu kepada siswa untuk bertanya dan mengeluarkan pendapat. Siswa menyimak materi yang diberikan sambil mengantuk akibat diselimuti rasa bosan mendengarkan penjelasan dari guru. Sebagian besar siswa berbicara dengan teman sebangkunya membahas hal lain yang tidak ada hubungannya dengan materi pelajaran. Selain itu, ada beberapa siswa yang kurang mampu mengerjakan tugas secara mandiri, terlihat ketika guru memberikan tugas masih banyak yang mengerjakan sambil bertanya kepada temannya. Permasalahan tersebut dapat disebabkan oleh banyak faktor, selain faktor internal dan eksternal pada diri siswa, faktor lainnya yang berpengaruh adalah faktor pendekatan belajar yang meliputi strategi dan model pembelajaran ceramah yang digunakan guru dalam kegiatan belajar mengajar sehingga kurang memberikan ruang bagi siswa untuk aktif dan berdiskusi. PPKn merupakan mata pelajaran yang memfokuskan pada pembentukan diri yang beragam dari segi agama, sosiokultural, bahasa usia, dan suku bangsa untuk menjadi Warga Negara Indonesia yang cerdas, trampil, dan berkarakter seperti yang diamanatkan oleh Pancasila dan UUD 1945. Tanpa pemahaman yang memadai pada mata pelajaran ini, siswa akan kesulitan memahami pelajaran PPKn di kemudian hari. Maka dari itu guru sebagai penggerak kelas dalam kegiatan belajar pembelajaran yang bisa diterapkan adalah model pembelajaran Kooperatif. Pembelajaran Kooperatif adalah model pembelajaran yang melibatkan partisipasi siswa dalam suatu kelompok kecil untuk saling berinteraksi dan belajar bekerja sama satu dengan lainnya. Berbagai tipe model pembelajaran Kooperatif dapat diterapkan untuk meningkatkan hasil belajar siswa. Snowball Throwing merupakan salah satu model pembelajaran Kooperatif yang dianggap mampu meningkatkan Hasil Belajar PPKn Siswa. Model Pembelajaran Kooperatif Tipe Snowball Throwing adalah suatu tipe model pembelajaran kooperatif dimana guru menggali potensi kepemimpinan siswa dalam kelompok dan keterampilan membuat-menjawab pertanyaan yang dipadukan melalui permainan imajinatif membentuk dan melempar bola salju. (Agus Suprijono: 2013)Penggunaan Model Pembelajaran Kooperatif Tipe Snowball Throwing cocok diterapkan di kelas XI IPS 1 SMA DwijendraDenpasar karena menurut pendapat para siswa kelax XI IPS 1 SMA Dwijendra Denpasar, mereka masih senang belajar sambil bermain. Model pembelajaran ini mampu mendorong siswa lebih aktif dan kreatif dalam kegiatan pembelajaran. Berdasarkan uraian diatas peneliti bermaksud melakukan penelitian dengan judul "Penerapan Model Pembelajaran Kooperatif Tipe Snowball Throwing untuk Meningkatkan Hasil Belajar Siswa Pada Mata Pelajaran PPKn Kelas XI IPS 1 SMA Dwijendra Denpasar Tahun Pelajaran 2018/2019"

\section{METODE}

Penelitian ini dilaksanakan di kelas XI IPS 1 SMA Dwijendra Denpasar yang beralamat di Jln. Kamboja Desa Dangin Puri Kangin Kecamatan Denpasar Utara, Kabupaten/Kota Denpasar, Provinsi Bali. Subjek penelitian ini adalah seluruh siswa kelas XI IPS1 SMA 
Dwijendra Denpasar Tahun Pelajaran

2018/2019. Objek dalam penelitian ini adalah sesuatu yang dapat diamati ketika model pembelajaran Kooperatif Tipe Snowball Throwing diterapkan yaitu hasil belajar PPKn siswa.

Teknik pengumulan data dalam penelitian ini menggunakan Observasi Partisipasi dan Dokumentsi. Teknik analisis data yang digunakan adalah analisis deskriptif kuantitatif dengan persentase. Analisis data deskriptif kuantitatif dengan persentase ini digunakan untuk menganalisis data Hasil Belajar Siswa Pada Mata Pelajaran PPKn.

\section{HASIL DAN PEMBAHASAN}

\section{Hasil Penelitian Siklus I}

Pembelajaran PPKn dengan menggunakan Model Pembelajaran Kooperatif Tipe Snowball Throwingsiklus I dilaksanakan pada tanggal 22 April 2019 selama 2 jam pelajaran yaitu $2 \times 45$ menit.

Berdasarkan Hasil Bejar PPKn Siswa, setelah diterapkan Model Pembelajaran Kooperatif Tipe Snowball Throwing pada siklus I, diperoleh data hasil belajar siswa pada mata pelajaran PPKn sebagai berikut:

Tabel 1. Persentase Skor Siklus I Observasi Hasil Belajar PPKn Siswa

\begin{tabular}{|c|c|c|}
\hline No & Indikator & $\begin{array}{c}\text { Skor Persentase } \\
\text { Siklusi }\end{array}$ \\
\hline 1 & $\begin{array}{l}\text { KELOMPK I } \\
\text { Pertanyaan: } \\
\text { Bagaimanakah makna HAM menurut kalian sendiri dari seluruh } \\
\text { penjelasan tersebut? } \\
\text { Jawaban: } \\
\text { 1. HAM merupakan Hak alamiah yang melekat dalam diri setiap manusia } \\
\quad \text { sejak Ia dilahirkan ke dunia } \\
\text { 2. HAM merupakan instrumen atau alat untuk menjaga harkat dan } \\
\quad \text { martabat manusia sesuai dengan kodrat kemanusiaannya yang luhur } \\
\text { Kesimpulan: } \\
\text { Ham merupakan segala sesuatu yang mendasar yang sudah melekat pada } \\
\text { diri manusia sejak lahir dan merupakan anugrah Tuhan Yang Maha Esa. } \\
\text { Contohnyahak untuk beragama, hak memperoleh pendidikan, dan hak } \\
\text { mengeluarkan pendapat. }\end{array}$ & $85,8 \%$ \\
\hline 2 & $\begin{array}{l}\text { KELOMPOK II } \\
\text { Pertanyaan: } \\
\text { Apa pengertian ham dan kewajiban dan berikan contoh! } \\
\text { Jawaban: } \\
\text { 1. Hak adalah sesuatu yang mutlak menjadi milik kita, hak merupakan } \\
\text { segala sesuatu yang harus didapatkan oleh setiap orang yang telah ada } \\
\text { sejak lahir bahkan sebelum lahir. Contohnya: hak untuk beragama, hak } \\
\text { memperoleh pendidikan dan mengeluarkan pendapat } \\
\text { 2. Kewajiban adalah sesuatu yang wajib dilaksanakan atau merupakan } \\
\text { keharusan. Contohnya: harus melaksanakan perintah orang tua, } \\
\text { dituntut untuk mematuhi tata tertib sekolah, harus mematuhi norma- } \\
\text { norma yang berlaku dalam masyarakat dan melaksanakan semua } \\
\text { ketentuan/peraturan perundang-undangan yang berlaku. } \\
\text { 3. Kesimpulan: }\end{array}$ & $83,4 \%$ \\
\hline
\end{tabular}




\begin{tabular}{|c|c|c|}
\hline & $\begin{array}{l}\text { Dapat mengetahui pengertian HAM, makna Ham, pasal yang } \\
\text { menyangkut HAM, serta pengertian hak dan kewajiban asasi, hak dan } \\
\text { kewajiban itu saling berkaitan dan mengetahui makna dari kewajiban } \\
\text { asasi tersebut. }\end{array}$ & \\
\hline 3 & $\begin{array}{l}\text { KELOMPOK III } \\
\text { Pertanyaan: } \\
\text { Jelaskan mengapa HAM dan Kewajiban asasi saling berkaitan? } \\
\text { Jawaban: } \\
\text { Karena manusia memiliki hak yang harus dipenuhi dan kewajiban yang } \\
\text { harus dilaksanakan agar semuanya seimbang, kita harus mementingkan } \\
\text { kewajban dari pada hak. } \\
\text { Kesimpulan: } \\
\text { 1. HAM merupakan hak yang melekat pada diri manusia sejak lahir dan } \\
\text { merupakan anugrah Tuhan Yang Maha Esa yang tidak bisa dibatasi } \\
\text { dan dicabut. Dan makna dari pada HAM merupakan hak alamiah yang } \\
\text { melekat dalam diri setiap manusia sejak Ia dilahirkan kedunia. } \\
\text { 2. Kewajiban asasi manusia juga memiliki makna sebagai kewajiban } \\
\text { dasar setiap manusia dimana apabila tidak dilaksanakan akan } \\
\text { memungkinkan tidak terlaksananya penegakan HAM karena keduanya } \\
\text { memiliki hubungan sebab akibat. }\end{array}$ & $87,5 \%$ \\
\hline 4 & $\begin{array}{l}\text { KELOMPOK IV } \\
\text { Pertanyaan: } \\
\text { Apa makna kewjiban asasi manusia? } \\
\text { Jawaban: } \\
\text { Sebagai kewajiban dasar setiap manusia dimana apabila tidak dilakukan } \\
\text { akan memungkinkan tidak terlaksana penegakan HAM. } \\
\text { Kesimpulan: } \\
\text { Harmonisasi hak dan kewajiban asasi manusia dalam perspektif pancasila } \\
\text { yaitu menyangkut tentang hal-hal hak asasi manusia/mendifinisikan } \\
\text { tentang ham dan memaknai setiap ham yang dimiliki }\end{array}$ & $66,7 \%$ \\
\hline 5 & $\begin{array}{l}\text { KELOMPOK V } \\
\text { Pertanyaan: } \\
\text { Sebutkan pengertian HAM, makna HAM, dan pasal yang menyangkut } \\
\text { HAM? } \\
\text { Jawaban: } \\
\text { 1. HAM adalah hak yang melekat pada diri manusia sejak lahir dan } \\
\text { merupakan anugrah Tuhan Yang Maha Esa yang tidak bisa di batasi } \\
\text { dan dicabut. } \\
\text { 2. Makna Ham adalah hak alamiah yang yang melekat pada diri manusia } \\
\text { atau hak yang sesuai dengan kodratnya. Dan merupakan alat untuk } \\
\text { menjaga harkat dan martabat manusia, tanpa ham manusia tidak dapat } \\
\text { hidup. } \\
\text { 3. Pasal 28A sampai pasal 28J. } \\
\text { Kesimpulan: } \\
\text { Hak asasi manusia adalah hak pokok yang melekat pada diri manusia sejak } \\
\text { lahir dan merupakan anugrah dari Tuhan Yang Maha Esa. Makna ham } \\
\text { suatu kebebasan dalam diri manusia yang tidak bisa di cabut jika dibatasi } \\
\text { akan terjadi pelanggaran HAM. Pasal yang menyangkut dalam HAM } \\
\text { adalah pasal 28A-28J. Makna kewajiban asasi manusia sebagai kewajiban } \\
\text { dasar setiap manusia dimana apabila tidak dilaksanakan akan } \\
\text { memungkinkan tidak terlaksananya penegakan HAM, karena keduanya } \\
\text { memiliki sebab-akibat. }\end{array}$ & $77,8 \%$ \\
\hline \multicolumn{2}{|r|}{ Rata-Rata } & $80,24 \%$ \\
\hline
\end{tabular}


Sumber: Data primer yang diolah

Adapun data perolehan nilai hasil belajar PPKn siswa pada siklus I yang di sajikan dalam bentuk tabel di bawah ini.

Tabel 2. Data Hasil Belajar PPKn Siswa Pada Siklus I

\begin{tabular}{|c|c|c|c|c|}
\hline \multirow[b]{2}{*}{ No } & \multirow[b]{2}{*}{ Nama Siswa } & \multirow[b]{2}{*}{ Nilai } & \multicolumn{2}{|c|}{ Ketuntasan } \\
\hline & & & Tuntas & Tidak Tuntas \\
\hline 1 & A.A. Ngurah Oka Surya Arimbawa & 77,8 & Tuntas & \\
\hline 2 & A.A. Sagung Tirtha Sari Dewi & 77,8 & Tuntas & \\
\hline 3 & A.A. Sagung Wulan Maharani & 85,8 & Tuntas & \\
\hline 4 & Desak putu sonya prema jyoti & 87,5 & Tuntas & \\
\hline 5 & Dewa Gede Agus Tirana & 85,8 & Tuntas & \\
\hline 6 & I Gede Krisna Sedana Putra & 85,8 & Tuntas & \\
\hline 7 & I Gusti Agung Gosa Wiswanatha & 83,4 & Tuntas & \\
\hline 8 & I Gusti Ayu Utamaningsih & 83,4 & Tuntas & \\
\hline 9 & I Kadek Dwi Cahya Andika & 87,5 & Tuntas & \\
\hline 10 & I Komang Palentino Adiputra & 77,8 & Tuntas & \\
\hline 11 & I Made Suartama & 85,8 & Tuntas & \\
\hline 12 & I Made Wida Nugraha & 85,8 & Tuntas & \\
\hline 13 & I Putu Yogi Upawana & 87,5 & Tuntas & \\
\hline 14 & I Wayan Divta Aryantara & 87,5 & Tuntas & \\
\hline 15 & I.A. Cynthia Sutha Garga Dewi & 66,7 & & Tidak Tuntas \\
\hline 16 & I.A. Ratih Laksemi Dewi & 83,4 & Tuntas & \\
\hline 17 & I.B. Gradika Pranama Adhi & 83,4 & Tuntas & \\
\hline 18 & Kadek Diah Chandra Pramesti & 77,8 & Tuntas & \\
\hline 19 & Kadek Geena Engrasia Gunawan & 83,4 & Tuntas & \\
\hline 20 & Komang Ayu Putri Dewi Lestari & 66,7 & & Tidak Tuntas \\
\hline 21 & Luh Amik Pramiyanti & 77,7 & Tuntas & \\
\hline 22 & Made Chintia Ari Prameswari & 66,7 & & Tidak Tuntas \\
\hline 23 & Made Yulia Anindita Pratiwi & 66,7 & & Tidak Tuntas \\
\hline 24 & Meilia Puspita Sari & 85,8 & Tuntas & \\
\hline 25 & Ni Kadek Kristina Putri & 87,5 & Tuntas & \\
\hline 26 & Ni Komang Trisna Arisedani & 66,7 & & Tidak Tuntas \\
\hline 27 & Ni Putu Ayu Risma Pramesti & 87,5 & Tuntas & \\
\hline 28 & Ni Putu Chayani Wipagandi & 85,8 & Tuntas & \\
\hline 29 & Ni Wayan Emytha Rasika Dewi & 83,4 & Tuntas & \\
\hline 30 & Oviana Mirangga Sari & 66,7 & & Tidak Tuntas \\
\hline 31 & Putu Gede Darma Putra & 87,5 & Tuntas & \\
\hline 32 & Riswan Ariyanto Umbu Deta & 83,4 & Tuntas & \\
\hline 33 & I Gusti Ngurah Agung Wipascitananda & 66,7 & & Tidak Tuntas \\
\hline 34 & I Komang Radya Suryanata & 77,8 & Tuntas & \\
\hline 35 & Putu Epin Sastrawan & 77,8 & Tuntas & \\
\hline
\end{tabular}

Berdasarkan data dari hasil observasi yang ditunjukan pada tabel di atas, dapat dilihat bahwa skor hasil belajar siswa pada mata pelajaran PPKn cukup baik setelah diterapkan Model Pembelajaran Kooperatif Tipe Snowball Throwing baik skor pada indikator maupun rata- ratanya. Rata-rata skor hasil belajar siswa pada siklus I adalah sebesar 80,24\%. Ini menunjukkan bahwa rata-rata skor hasil belajar siswa pada mata pelajaran PPKn telah melebihi indikator keberhasilan yaitu $75 \%$. Namun karena terdapat satu indikator yang belum 
mencapai indikator keberhasilan yaitu kelompok IV yang hanya mendapat $66,7 \%$ maka diperlukan tindakan lanjutan pada siklus II.

\section{Refleksi Siklus I}

Tahap ini peneliti sebagai guru yang menerapkan Model Pembelajaran Kooperatif Tipe Snowball Throwing mengevaluasi proses dan hasil kegiatan pembelajaran PPKn mengenai Makna Hak Asasi Manusia dan Makna Kewajiban Asasi Manusia dalam siklus I. Meskipun rata-rata skor hasil belajar siswa pada mata pelajaran PPKn pada siklus I telahmencapai $80,24 \%$, namun satu indikator hasil belajar siswa pada mata pelajaran PPKn masih berada dibawah 75\%. Indikator pada kelompok IV hanya menunjukan perentase skor sebesar $66,7 \%$. Hal ini dikarenakan siswa belum pernah melakukan permainan tersebut sebelumnya sehingga masih terdapat kebingungan dan kesalahan dalam pelaksanaanya.

\section{Hasil Penelitian Siklus II}

Berdasarkan hasil bejar siswa pada mata pelajaran PPKn, setelah diterapkan Model Pembelajaran Kooperatif Tipe Snowball Throwing pada siklus II, diperoleh data hasil belajar siswa pada mata pelajaran PPKn sebagai berikut:

Berdasarkan data dari hasil observasi, dapat dilihat bahwa skor hasil belajar PPKn siswa telah meningkat setelah diterapkannya Model Pembelajaran Kooperatif Tipe Snowball Throwing pada siklus II baik skor per indikator maupun rata-ratanya. Rata-rata skor hasil belajar PPKn siswa pada silus ke II adalah sebesar 91,84\%. Skor masing-masing indikator juga telah mencapai indikator keberhasilan melebihi $75 \%$.

Adapun data perolehan nilai hasil belajar PPKn siswa pada siklus I yang di sajikan dalam bentuk tabel di bawah ini.

Tabel 3. Data Hasil Belajar PPKn Siswa Pada Siklus II

\begin{tabular}{|l|l|c|l|l|}
\hline \multirow{2}{*}{ No } & \multicolumn{1}{|c|}{ Nama Siswa } & \multicolumn{2}{|c|}{ Ketuntasan } \\
\cline { 4 - 5 } & & Nilai & Tuntas & Tidak Tuntas \\
\hline 1 & A.A. Ngurah Oka Surya Arimbawa & 92,3 & Tuntas & \\
\hline 2 & A.A. Sagung Tirtha Sari Dewi & 92,3 & Tuntas & \\
\hline 3 & A.A. Sagung Wulan Maharani & 92,9 & Tuntas & \\
\hline 4 & Desak putu sonya prema jyoti & 93,4 & Tuntas & \\
\hline 5 & Dewa Gede Agus Tirana & 93,4 & Tuntas & \\
\hline 6 & I Gede Krisna Sedana Putra & 91,7 & Tuntas & \\
\hline 7 & I Gusti Agung Gosa Wiswanatha & 91,7 & Tuntas & \\
\hline 8 & I Gusti Ayu Utamaningsih & 88,9 & Tuntas & \\
\hline 9 & I Kadek Dwi Cahya Andika & 92,9 & Tuntas & \\
\hline 10 & I Komang Palentino Adiputra & 92,3 & Tuntas & \\
\hline 11 & I Made Suartama & 92,9 & Tuntas & \\
\hline 12 & I Made Wida Nugraha & 92,9 & Tuntas & \\
\hline 13 & I Putu Yogi Upawana & 91,7 & Tuntas & \\
\hline 14 & I Wayan Divta Aryantara & 93,4 & Tuntas & \\
\hline 15 & I.A. Cynthia Sutha Garga Dewi & 88,9 & Tuntas & \\
\hline 16 & I.A. Ratih Laksemi Dewi & 88,9 & Tuntas & \\
\hline
\end{tabular}




\begin{tabular}{|l|l|l|l|l|}
\hline 17 & I.B. Gradika Pranama Adhi & 92,3 & Tuntas & \\
\hline 18 & Kadek Diah Chandra Pramesti & 93,4 & Tuntas & \\
\hline 19 & Kadek Geena Engrasia Gunawan & 92,9 & Tuntas & \\
\hline 20 & Komang Ayu Putri Dewi Lestari & 92,3 & Tuntas & \\
\hline 21 & Luh Amik Pramiyanti & 88,9 & Tuntas & \\
\hline 22 & Made Chintia Ari Prameswari & 88,9 & Tuntas & \\
\hline 23 & Made Yulia Anindita Pratiwi & 92,3 & Tuntas & \\
\hline 24 & Meilia Puspita Sari & 88,9 & Tuntas & \\
\hline 25 & Ni Kadek Kristina Putri & 93,4 & Tuntas & \\
\hline 26 & Ni Komang Trisna Arisedani & 91,7 & Tuntas & \\
\hline 27 & Ni Putu Ayu Risma Pramesti & 93,4 & Tuntas & \\
\hline 28 & Ni Putu Chayani Wipagandi & 92,9 & Tuntas & \\
\hline 29 & Ni Wayan Emytha Rasika Dewi & 88,9 & Tuntas & \\
\hline 30 & Oviana Mirangga Sari & 92,3 & Tuntas & \\
\hline 31 & Putu Gede Darma Putra & 93,4 & Tuntas & \\
\hline 32 & Riswan Ariyanto Umbu Deta & 91,7 & Tuntas & \\
\hline 33 & I Gusti Ngurah Agung Wipascitananda & 88,9 & Tuntas & \\
\hline 34 & I Komang Radya Suryanata & 91,7 & Tuntas & \\
\hline 35 & Putu Epin Sastrawan & 91,7 & Tuntas & \\
\hline
\end{tabular}

\section{Refleksi Siklus II}

Hasil penelitian pada siklus II menunjukan adanya peningkatan persentase di masing-masing indikator hasil belajar siswa, dengan peningkatan tesebut menunjukan bahwa kelemahan yang terjadi pada pelaksanaan siklus I dapat diperbaiki pada pelaksanaan siklus II. Karena pada siklus II skor hasil belajar PPKn siswa telah mencapai indikator keberhasilan yaitu: $75 \%$ baik skor per indikator maupun rataratanya, maka tidak diperlukan kelanjutan tindakan selanjutnya.

\section{Pembahasan Hasil Tindakan}

Tahap-tahap penelitian ini adalah tahap perencanaan, pelaksanaan tindakan, pengamatan, dan refleksi. Data yang di peoleh dari observasi pada setiap akhir siklus analisis unruk menemukan persentase setiap indikator maupun skor rata-rata. Selanjutnya skor observasi siklus I da siklus II dibandingkan untuk mengetahui persentase peningkatannya. Baik peningkatan absolut maupun peningkatan relatif. Peningkatan persentase skor hasil belajar PPKn siswa berdasarkan lembar observasi dapat dilihat pada tabel berikut:

Tabel 4. Persentase Peninkatan Hasil Belajar PPKn Siswa Siklus I ke Siklus II

\begin{tabular}{|c|c|c|c|c|c|}
\hline No & Kelompok & $\begin{array}{c}\text { Skor } \\
\text { Siklus } \\
\text { I }\end{array}$ & $\begin{array}{c}\text { Skor } \\
\text { Siklus } \\
\text { II }\end{array}$ & $\begin{array}{c}\text { Peningkatan } \\
\text { Absolut } \\
\text { Siklus I }\end{array}$ & $\begin{array}{c}\text { Peningkatan } \\
\text { Relatif } \\
\text { Siklus II }\end{array}$ \\
\hline 1 & I & $85,8 \%$ & $88,9 \%$ & $3,1 \%$ & $3,7 \%$ \\
\hline 2 & II & $83,4 \%$ & $92,9 \%$ & $9,5 \%$ & $11,4 \%$ \\
\hline
\end{tabular}




\begin{tabular}{|c|c|c|c|c|c|}
\hline 3 & III & $87,5 \%$ & $93,4 \%$ & $5,9 \%$ & $6,8 \%$ \\
\hline 4 & IV & $66,7 \%$ & $92,3 \%$ & $25,6 \%$ & $38,4 \%$ \\
\hline 5 & V & $77,8 \%$ & $91,7 \%$ & $13,9 \%$ & $17,9 \%$ \\
\hline \multicolumn{2}{|c|}{ Rata-rata } & $\mathbf{8 0 , 2 4 \%}$ & $\mathbf{9 1 , 8 4 \%}$ & $\mathbf{1 1 , 6 \%}$ & $\mathbf{1 5 , 6 \%}$ \\
\hline
\end{tabular}

Peningkatan skor hasil belajar PPKn siswa dapat dilihat dari peningkatan persentaseskor observasi baik per indikator maupun skor rata-rata. Peningkatan skor tertinggi berada pada indikator kelompok IV yaitu sebesar $25,6 \%$ sedangkan peningkatan skor terendah berada pada indikator I yaitu sebesar $3,1 \%$ selain itu dari analisis data dapat diketahui bahwa peningkatan skor rata-rata hasil belajar PPKn siswa dari siklus I ke siklus II adalah $4 \%$.

\section{PENUTUP}

Berdasarkan hasil penelitian dapat disimpulkan bahwa Penerapan Model Pembelajaran Kooperatif Tipe Snowball Throwing dapat meningkatkan Hasil Belajar PPKn Siswa Kelas XI IPS1 SMA Dwijendra Denpasar Tahun Pelajaran 2018/2019. Hal tersebut didukung dengan data penelitian yang menunjukkan adanya peningkatan pada indikator yang merupakan hasil belajar siswa.

Skor rata-rata Hasil Belajar PPKn Siswa juga meningkat dari siklus I ke siklus II. Hal ini dibuktikan dengan adanya peningkatan persentase Hasil Belajar PPKn dari siklus I ke siklus II melalui observasi. Hasil observasi siklus I sebesar $80,24 \%$ dan siklus II sebesar
91,84\%, hal ini berarti terdapat peningkatan sebesar $11,6 \%$.

\section{DAFTAR PUSTAKA}

Crow, Lester D \& Alice Crow. 1958. Educational Psychology, First Editon.American Book Company, New York.

Darwati, Mas \& Mahendra, Putu Ronny Angga. 2019. Efektivitas Pembelajaran PPKn Berbasis Teknohumanistik Dalam Pembentukan Karakter Siswa Kelas X Jasa Boga 2 di SMK Prshanti Nilayam Kuta Tahun Pelajaran 2017/2018. Singaraja: FHIS Universitas Pendidikan Ganesha.

Ellen Julianti. (2015). "Model Pembelajaran Kooperatif Tipe Snowball Throwing untuk Meningkatkat Keaktifan, Dan Hasil Belajaran Siswa Pada Mata Pelajaran Teknik Dasar Otomatis Kelas XI di SMA Dwijendra Denpasar". Skripsi. Universitas Negeri Yogyakarta.

Hamalik. Oemar. 2003. Metode Belajar dan Kesulitan-KesulitanBelajar.Bandung: Remaja Karya.

Mahendra, Putu Ronny Angga. Civic Culture Ngayah Dalam Pembelajaran PPKn. AP3KnI Jateng: Jurnal PPKn Vol. 6 No. 1 Januari 2018.

Miftahul Huda. (2013). Model-Model Pengajarandan Pembelajaran Isu-Isu Metodis dan Paradigmatis. Yogyakarta: Pustaka Pelajar Offset.

Munadi, Yudhi. 2008. Media Pembelajaran:Suatu Pendekatan Baru.Jakarta: Gaung Persada Press.

Thorndike, E.L. 1913b. Educational Psychology. Dalam D.H. Schunk. Learning Theories An Educational Perspective. Yogyakarta: Pustaka Pelajar. 
Winaya, Astra,2017. "Efektivitas Pengembangan Nilai-nilai Karakter Pada Peserta Pesraman Kilat Tingkat Dasar di Desa Pekraman Selan Bawak,Keamatan Marga,Kabupaten Tabanan-Bali. ’Jurnal Widya Accarya.Fakultas Keguruan dan Ilmu Pendidikan Universitas Dwijendra, EJurnal.ac.id., Denpasar.

Witherington. 1952. Kecakapan Belajar Siswa. Jakarta: PT Raja Grafindo.. 